\title{
DAMPAK PENGELOLAAN SUMBER DAYA MANUSIA USAHA MIKRO, KECIL DAN MENENGAH DARI SEGI KOMPETENSI TERHADAP KINERJA UMKM (STUDI KASUS: UMKM DESA TRUSMI-CIREBON)
}

\author{
Wenty Febrianti dan Budiman Abdulah \\ STIE Muhammadiyah Jakarta \\ Email: wentystiemj@gmail.com dan budiman_ide@yahoo.com
}

\section{Abstract}

The Indonesian government pays attention to micro, small and medium enterprises (UMKM) by establishing a forum for UMKM under the ministry of cooperatives and SMEs, MSMEs have an important role in improving the economy of a region and even the State. Likewise with Trusmi Village, Plered Cirebon District, the existence of MSMEs can help the regional economy, but the existence of MSMEs is inseparable from the role of MSME HR in improving the performance of MSMEs so that MSME HR management needs to receive special attention, especially the competencies that must be possessed by HR involved in MSME activities. this. This study aims to determine the impact of human resource management of Micro, Small and Medium Enterprises in terms of competence on the performance of MSMEs. Data collection techniques used questionnaires, interviews, and observations. Respondents were 64 MSMEs registered at the Cooperative and UMKM Office of Cirebon City, Trusmi Village, with a sample of 64 respondents. The method used in this research is a survey method using a descriptive analysis approach. Data processing techniques are used to determine the relationship or correlation between variables using linear regression. The results of this study indicate a positive and significant influence between competence and the performance of MSMEs. With this research, it is expected that the performance of MSMEs will be better by paying attention to the management of MSME HR by providing training and development so as to increase the competence of MSME HR.

Keywords: competence; MSME performance; Human resource

\begin{abstract}
Abstrak
Pemerintah Indonesia menaruh perhatian terhadap usaha mikro, kecil dan menengah (UMKM) dengan mendirikan wadah bagi UMKM dibawah kementerian koperasi dan ukm, UMKM memiliki peranan penting dalam meningkatkan perekonomian suatu daerah bahkan Negara. Begitupun dengan Desa Trusmi Kecamatan Plered Cirebon, keberadaan UMKM dapat membantu perekonomian daerahnya, akan tetapi keberadaan UMKM tidak terlepas dari peran serta SDM UMKM dalam meningkatkan kinerja UMKM sehingga pengelolaan SDM UMKM perlu mendapat perhatian khusus terutama kompetensi yang harus dimiliki oleh SDM yang terlibat dalam kegiatan UMKM ini. Penelitian ini bertujuan untuk mengetahui dampak pengelolaan sumber daya manusia Usaha Mikro, Kecil dan Menengah dari segi kompetensi terhadap Kinerja UMKM. Teknik pengumpulan
\end{abstract}


Dampak Pengelolaan Sumber Daya Manusia Usaha Mikro, Kecil dan Menengah dari Segi Kompetensi Terhadap Kinerja UMKM (Studi Kasus: UMKM Desa Trusmi-

Cirebon)

data menggunakan kuesioner, wawancara, dan observasi. Responden adalah UMKM yang terdaftar di Dinas Koperasi dan UMKM Kota Cirebon Desa Trusmi, sebanyak 64 UMKM, dengan sampel sebanyak 64 responden. Metode yang digunakan dalam penelitian ini adalah metode survei dengan menggunakan pendekatan deskriptif analisis. Teknik pengolahan data digunakan untuk mengetahui hubungan atau korelasi antar variabel dengan menggunakan regresi linier. Hasil penelitian ini menunjukkan adanya pengaruh positif dan signifikan antara kompetensi dengan kinerja UMKM. Dengan adanya penelitian ini diharapkan kinerja UMKM semakin baik dengan memperhatikan pengelolaan SDM UMKM dengan cara pemberian pelatihan dan pengembangan sehingga meningkatkan kompetensi SDM UMKM.

Kata kunci: kompetensi; kinerja UMKM; SDM

\section{Coresponden Author}

Email: wentystiemj@gmail.com Artikel dengan akses terbuka dibawah lisensi

\section{Pendahuluan}

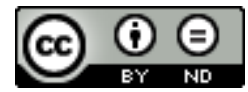

Pekembangan era globalisasi di masa sekarang ini menjadi sangat mudah dijangkau bahkan sudah tidak ada batasan lagi dalam mencari informasi terkait dengan kehidupan manusia, pertumbuhan ekonomi global serta politik, kemudahan mengakses segala sesuatu di era digitalisasi juga mempengaruhi pertumbuhan ekonomi dalam suatu Negara. Di Indonesia dalam memajukan usaha mikro, kecil dan menengah (UMKM), dalam era internet of thinks (IOT) memudahkan para pelaku UMKM memasarkan usaha nya dalam ruang lingkup yang lebih luas. Oleh karena itu demi mengikuti perkembangan zaman sekarang yang semuanya serba digitalisasi mengharuskan sumber daya manusia (SDM) yang ada di UMKM perlu mempersiapkan diri dengan adanya perbaikan dari segi pengelolaan SDM nya. Pengelolaan SDM bagi UMKM merupakan suatu keterampilan yang penting yang harus dimiliki oleh para pelaku UMKM, demi mewujudkan peningkatan kinerja UMKM sehingga dapat terus memberikan kontribusi terhadap perekonomian suatu Negara. Berikut ini adalah kendala yang dihadapi para pelaku UMKM berdasarkan hasil survey yang dilakukan oleh MarkPlus Insight yang ditulis oleh (Bachdar, 2016) pada marketeers.com:

Tabel 1

Kendala Para Pelaku UMKM

\begin{tabular}{ccc}
\hline No. & Kendala & Presentase \\
\hline 1. & Teknologi & $53.6 \%$ \\
\hline 2. & Pengelolaan SDM & $49.4 \%$ \\
\hline 3. & Proses Produksi & $31.4 \%$ \\
\hline \multicolumn{3}{c}{ Sumber: Marketeers.com (Desember 2016) }
\end{tabular}


Dan berdasarkan hasil riset worldbank sebagaimana yang ditulis oleh (Putra et al., 2018) pada merdeka.com ada empat permasalahan yang dihadapi oleh para pelaku UMKM sebagai berikut:

\section{Tabel 2}

\section{Permasalahan UMKM}

\begin{tabular}{cc}
\hline No. & Permasalah UMKM \\
\hline 1. & Tidak ada nya akses pembiayaan \\
\hline 2. & Tidak memiliki akses peluang dan usaha \\
\hline 3. & Tidak memiliki kapasitas SDM dan kelembagaan UMKM \\
\hline 4. & Masalah regulasi dan birokrasi \\
\hline & Sumber: Merdeka.com (Juli 2018)
\end{tabular}

Berdasarkan tabel 1 dan tabel 2 menunjukan bahwa rata-rata pengelolaan SDM menjadi masalah yang sering dihadapi UMKM. Sedangkan berdasarkan hasil pra penelitian disimpulkan bahwa salah satu faktor yang mempengaruhi kinerja UMKM di Desa Trusmi adalah kompetensi SDM yang berada di UMKM. Pengungkapan kompetensi sebagai salah satu faktor yang dapat meningkatkan kinerja UMKM telah dilakukan oleh (Apriliani O. D, R. AJ. E. P., Suparwono., 2016a), (Sulistyandari, Widiastuti, \& Martini, 2016), dan (Widjadja, Alamsyah, Rohaeni, \& Sukanjie, 2018) dalam penelitiannya mereka menemukan bahwa yang mempengaruhi kinerja UMKM yaitu kompetensi. (Apriliani O. D, R. AJ. E. P., Suparwono., 2016a), (Sulistyandari et al., 2016), dan (Widjadja et al., 2018), mengemukakan bahwa kompetensi berpengaruh terhadap kinerja UMKM. akan tetapi dalam penelitian (Dharmanegara, Sitiari, \& Wirayudha, 2016) menemukan bahwa kompetensi tidak berpengaruh terhadap kinerja UMKM, sehingga terdapat gap dari hasil penelitian yang telah dilakukan. Oleh karena itu diperlukan suatu kajian yang komprehensif mengenai faktor-faktor yang berpengaruh terhadap kinerja UMKM.

Tujuan dari penelitian ini adalah untuk mengungkapkan apakah faktor kompetensi juga berpengaruh terhadap kinerja UMKM di Desa Trusmi Kecamatan Plered Kabupaten Cirebon, Jawa Barat.

\section{A. Kompetensi}

Menurut (Jeffrey \& Soleman, 2017) kompetensi adalah karakteristik yang mendasari orang yang menunjukkan cara berperilaku atau berpikir, yang menggeneralisasi diberbagai macam situasi dan bertahan untuk jangka waktu yang lama. Sedangkan menurut (Asumeng, 2014) kompetensi pertama kali diperkenalkan oleh White pada tahun 1959 untuk menggambarkan karakteristik individu, secara khusus dikatakan bahwa kecerdasan atau potensi kognitif ada pengaruhnya terhadap motivasi dan pada gilirannya akan memprediksi hasil kinerja ditempat kerja. (Hadiyatno, 2012) mengatakan bahwa kompetensi adalah an underlying characteristi's of an individual which is causally related to criterion referenced effective and or superior performance in a job or situation. Karakteristik yang mendasari seseorang dan berkaitan dengan efektifitas kinerja individu dalam 
pekerjaanya. (Rivai, 2013) mendefinisikan kompetensi sebagai karakter yang mendasar yang dimiliki seseorang yang berpengaruh langsung terhadap atau dapat memprediksikan kinerja yang sangat baik. (Widjadja et al., 2018) menerangkan bahwa aspek-aspek kompetensi yaitu: 1). Pengetahuan; 2). Keterampilan; 3). Kemampuan atau karakteristik kepribadian. Sedangkan menurut (Syafarudin \& Sudiarditha, 2018) karakteristk kompentensi adalah sebagai berikut: Motives; Traits; Self Concept; Knowledge; Skills.

\section{B. Kinerja UMKM}

(Jeffrey \& Soleman, 2017) menjelaskan bahwa kinerja kerja merupakan bagian penting dari manajemen sumber daya manusia dan merupakan kriteria penting untuk hasil dan keberhasilan suatu organisasi. Menurut (Jeffrey \& Soleman, 2017) menyatakan bahwa manajemen kinerja adalah proses mengkonsolidasikan penetapan tujuan, penilaian dan pengembangan kinerja ke dalam sistem bersama tunggal, yang bertujuan untuk memastikan kinerja karyawan mendukung tujuan strategis perusahaan. Sedangkan (Armstrong, 2016) mendifinisikan performance management is the continuous process of improving performance by setting goals that are aligned to the strategic goals of the organization, planning performance to achieve the goals, reviewing progress, and developing the knowledge, skills and abilities of people. Manajemen kinerja adalah proses berkesinambungan untuk meningkatkan kinerja dengan menetapkan tujuan yang selaras dengan tujuan strategis organisasi, merencanakan kinerja untuk mencapai tujuan, mengkaji kemajuan, dan mengembangkan pengetahuan, keterampilan dan kemampuan manusia. Balanced scorecard adalah suatu konsep manajemen yang membantu menerjemahkan strategi kedalam tindakan. Adapun aspek pengukuran kinerja melalui pendekatan balanced scorecard adalah sebagai berikut: (1). Keuangan; (2) Pelanggan; (3) Proses bisnis internal; (4) Pembelajaran dan pertumbuhan (Widaningrum, 2014).

\section{Hipotesis Penelitian}

Hasil penelitian (Apriliani O. D, R. AJ. E. P., Suparwono., 2016b), (Sulistyandari, Widiastuti, \& Martini, 2017), dan (Widjadja et al., 2018), mengemukakan bahwa kompetensi berpengaruh terhadap kinerja UMKM. Berdasarkan uraian tersebut, maka dibuatkan kerangka pikir sebagai berikut:

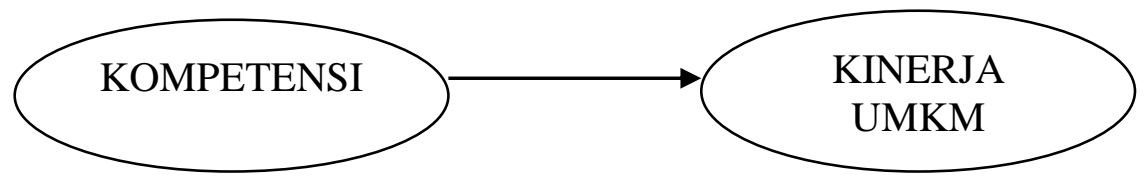

Gambar 1 Model Penelitian

Sumber: Data diolah peneliti

Berdasarkan hasil penelitian terdahulu terkait dan model penelitian, maka hipotesis dalam proses penelitian ini ditetapkan sebagai berikut: 
Ha: Ada pengaruh faktor kompetensi terhadap kinerja UMKM

\section{Metode Penelitian}

Metode yang digunakan dalam penelitian ini adalah metode survai dengan menggunakan analisis deskriptif dengan menggunakan pendekatan studi korelasi dengan melakukan uji regresi, uji t dan koefisian determinasi. Pada penelitian ini variabel penelitian yang diamati adalah variabel independen atau variabel bebas yang terdiri dari kompetensi dan variabel dependen atau variabel terikat yaitu kinerja UMKM.

Tabel 3

Definisi Operasional dan Pengukuran Variabel

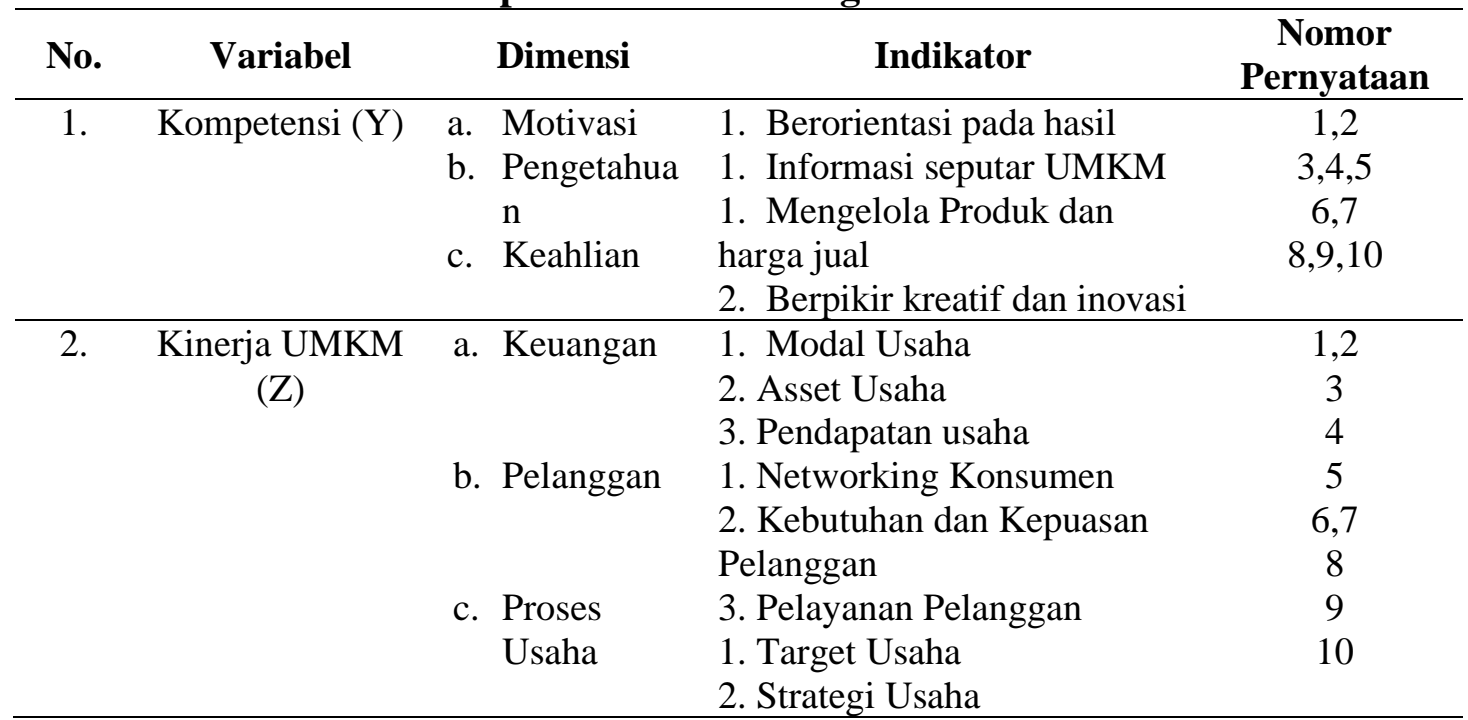

Sumber: Data diolah penulis dari berbagai sumber (2019)

Populasi adalah 64 UMKM yang terdaftar di Dinas Koperasi dan UMKM Kota Cirebon Desa Trusmi, dengan sampel sebanyak 64 responden. Data primer bersumber dari kuesioner yang dibagikan langsung kepada pelaku UMKM di Desa Trusmi. Jenis data yang digunakan adalah data primer dan data sekunder. Data primer bersumber dari kuesioner yang dibagikan langsung kepada para pelaku UMKM. Data sekunder bersumber dari studi pustaka melalui berbagai buku, jurnal dan artikel terkait. Dalam penelitian ini metode analisis data menggunakan analisis deskriptif yang digunakan untuk menganalisa data dengan cara mendeskripsikan data yang telah terkumpul. Kemudian dengan melakukan pengujian instrumen penelitian melalui uji validitas dan uji reliabilitas. Selanjutnya melakukan analisis koefisien determinasi untuk mengetahui besarnya kontribusi pengaruh variabel bebas terhadap variabel terikat. Berikutnya untuk menjawab hipotesis yang diajukan maka dilakukan uji t. Pengolahan data, perhitungan korelasi dan teknik pengujian dilakukan dengan bantuan komputer melalui aplikasi SPSS versi 17. 
Dampak Pengelolaan Sumber Daya Manusia Usaha Mikro, Kecil dan Menengah dari

Segi Kompetensi Terhadap Kinerja UMKM (Studi Kasus: UMKM Desa Trusmi-

Cirebon)

\section{Hasil dan Pembahasan}

\section{Karakteristik Responden}

Hasil dari jawaban karakteristik responden menunjukan bahwa responden dengan jenis kelamin wanita lebih banyak daripada responden pria, yaitu sebanyak 38 responden $(59 \%)$, sedangkan sebanyak 26 orang (41\%) merupakan responden pria. Selanjutnya untuk responden berdasarkan tingkat pendidikan yaitu S1 sebanyak 9 responden (14\%), SMA dengan jumlah 38 responden (59\%), kemudian SMP sebanyak 11 responden (17\%), dan tingkat pendidikan SD sebanyak 6 responden $(9 \%)$. Kemudian untuk responden berdasarkan usia dengan kategori usia 17-30 tahun sebanyak 31 responden (48\%), kategori usia 31-45 tahun sebanyak 23 responden $(36 \%)$ dan untuk usia $>45$ tahun sebanyak 10 responden $(16 \%)$.

\section{Uji Validitas dan Reliabilitas}

Uji validitas variabel kompetensi, dan kinerja UMKM dilakukan melalui SPSS, untuk hasil uji validitas variabel kompetensi hasilnya sudah valid dari setiap pernyataan kuesioner karena Corrected Item Total Correlation sudah melebihi 0,3. Akan tetapi pada uji validitas kinerja UMKM ada satu pernyataan kuesioner yang tidak valid karena Corrected Item Total Correlation kurang dari 0,3 oleh karena itu dilakukan uji validitas ulang dengan menghilangkan item yang tidak valid. Setelah dilakukan uji validitas ulang hasilnya menunjukkan bahwa indikator yang diajukan telah valid karena Corrected Item Total Correlation lebih besar dari 0,3. Kemudian pada uji reliabilitas menunjukan bahwa variabel $\mathrm{X}$ mengenai kompetensi dengan cronbach alpha sebesar 0,925 lebih besar dari 0,6 maka dapat dinyatakan reliabel. Variabel Y mengenai kinerja dengan cronbach alpha sebesar 0,876 lebih besar dari 0,6 maka dapat dinyatakan reliabel. Maka dapat disimpulkan bahwa seluruh instrument yang digunakan adalah reliabel.

3. Analisis Regresi.

Analisa regersi linier menunjukan bahwa:

\section{Tabel 4}

Hasil Uji Regresi

\begin{tabular}{llllllll}
\hline \multirow{2}{*}{ Model } & \multicolumn{3}{l}{$\begin{array}{l}\text { Unstandardized } \\
\text { Coefficients }\end{array}$} & \multicolumn{2}{l}{$\begin{array}{l}\text { Standardized } \\
\text { Coefficients }\end{array}$} & & \multicolumn{3}{c}{$\begin{array}{l}\text { Collinearity } \\
\text { Statistics }\end{array}$} \\
& B & $\begin{array}{l}\text { Std. } \\
\text { Eror }\end{array}$ & Beta & T & Sig & Tolerance & VIF \\
\hline (Constant) & 3.450 & 2.165 & & 1.594 & .116 & & \\
Kompetensi (X) & .778 & .058 & .863 & 13.437 & .000 & 1.000 & 1.000 \\
\hline & \multicolumn{7}{c}{ Sumber: Data primer diolah $(2020)$} \\
\end{tabular}

Dari hasil diatas dapat dibuat model persamaan regresinya sebagai berikut:

$$
\mathrm{Y}=\mathbf{3 , 4 5 0}+\mathbf{0 , 7 7 8 X}+\mathrm{e}
$$


Dari persamaan regresi diatas diketahui nilai konstanta sebesar 3,450 artinya jika kompetensi konstan maka kinerja UMKM sebesar 3,450. Koefisien regresi X sebesar 0,778 menyatakan bahwa setiap kenaikan X (kompetensi bertambah 1\%) maka kinerja UMKM akan mengalami peningkatan sebesar 0,778 .

\section{Uji Hipotesis}

Pengujian hipotesis dilakukan dengan menggunakan program SPSS Versi 17. Kemudian Untuk melihat pengaruh dan signifikan terhadap variabel independen terhadap variabel dependen maka dilakukan pengujian hipotesis uji $t$ dengan hasil sebagai berikut:

\section{Tabel 5}

Hasil Uji Hipotesis

\begin{tabular}{llccccccc}
\hline \multicolumn{1}{c}{ Model } & \multicolumn{2}{c}{$\begin{array}{c}\text { Unstandardized } \\
\text { Coefficients }\end{array}$} & \multicolumn{3}{c}{$\begin{array}{c}\text { Standardized } \\
\text { Coefficients }\end{array}$} & \multicolumn{3}{c}{$\begin{array}{c}\text { Collinearity } \\
\text { Statistics }\end{array}$} \\
& $\mathbf{B}$ & $\begin{array}{c}\text { Std. } \\
\text { Eror }\end{array}$ & Beta & T & Sig & Tolerance & VIF \\
& & & & & & & \\
(Constant) & 3.450 & 2.165 & & & 1.594 & .116 & & \\
Kompetensi $(\mathrm{X})$ & .778 & .058 & .863 & 13.437 & .000 & 1.000 & 1.000 \\
\hline
\end{tabular}

Sumber: Data primer diolah (2020)

\section{Hipotesis: Pengaruh kompetensi terhadap kinerja UMKM}

Ho: Tidak ada pengaruh signifikan dari kompetensi terhadap kinerja UMKM

Ha: Ada pengaruh signifikan dari kompetensi terhadap kinerja UMKM

Berdasarkan tabel 5 menunjukan bahwa nilai thitung sebesar 13.437 dan $t_{\text {tabel }}$ sebesar 1,669 maka nilai $t_{\text {hitung }}$ lebih besar dari nilai $t_{\text {tabel }}$ dan nilai signifikansinya sebesar 0,000 kurang dari 0,05, sehingga keputusan yang dapat diambil adalah $\mathrm{Ha}$ diterima dan Ho ditolak berarti ada pengaruh positif dan signifikan antara variabel kompetensi terhadap variabel kinerja UMKM.

5. Koefisien Determinasi.

Koefisien determinasi digunakan untuk mengetahui besarnya kontribusi dari keseluruhan variabel bebas pengaruhnya terhadap variabel terikat, sedangkan sisanya dipengaruhi oleh variabel bebas yang tidak digunakan dalam model penelitian.

\section{Tabel 6}

Hasil Koefisien Determinasi

\begin{tabular}{ccccc}
\hline Model & R & R Square & $\begin{array}{c}\text { Adjusted R } \\
\text { Square }\end{array}$ & $\begin{array}{c}\text { Std. Error of } \\
\text { the Estimate }\end{array}$ \\
\hline 1 & $.863^{\mathrm{a}}$ & .744 & .740 & 1.992 \\
\hline \multicolumn{5}{c}{ Sumber: Data primer diolah (2020) }
\end{tabular}

Nilai korelasi berdasarkan tabel 6 diperoleh $\mathrm{R}$ sebesar 0,863 angka ini menggambarkan adanya korelasi yang positif dan signifikan antara variabel kompetensi terhadap kinerja UMKM. Dengan nilai $\mathrm{R}=0,863$ sesuai dengan tabel interprestasi koefisien korelasi pengaruh variabel kompetensi terhadap kinerja 
karyawan tersebut dikategorikan kuat. Nilai $\mathrm{r}^{2}$ ( $R$ Square) adalah sebesar 0,744 hal ini berarti $74,4 \%$ kinerja UMKM dipengaruhi oleh variabel kompetensi, dan sisanya sebesar $25,6 \%$ disebabkan oleh faktor-faktor lain diluar model penelitian. Kemudian untuk melihat korelasi antar dimensi maka dilakukan uji matriks korelasi dengan hasil sebagai berikut:

Tabel 7

Matriks Korelasi Antar Dimensi

\begin{tabular}{llccc}
\hline $\begin{array}{c}\text { Variabel } \\
\text { Independen }\end{array}$ & \multicolumn{1}{c}{ Dimensi } & $\begin{array}{c}\text { Keuangan } \\
\mathbf{Y}_{\mathbf{1}}\end{array}$ & $\begin{array}{c}\text { Pelanggan } \\
\mathbf{Y}_{\mathbf{2}}\end{array}$ & $\begin{array}{c}\text { Proses Usaha } \\
\mathbf{Y}_{\mathbf{3}}\end{array}$ \\
\hline Kompensasi & Motivasi & $.705^{* *}$ & $.784^{* *}$ & $.709^{* *}$ \\
$(\mathrm{X})$ & Pengetahuan & $.660^{* *}$ & $.685^{* *}$ & $.628^{* *}$ \\
& Keahlian & $.734^{* *}$ & $.827^{* *}$ & $.677^{* *}$ \\
\hline
\end{tabular}

Sumber: Data primer diolah (2020)

Berdasarkan Tabel matriks korelasi antar dimensi maka hasil yang diperoleh adalah sebagai berikut:

\section{Kompetensi terhadap Kinerja UMKM}

Untuk variabel kompetensi pada dimensi motivasi terhadap dimensi kinerja UMKM yang pertama yaitu keuangan memiliki hubungan kuat sebesar 0,705, kemudian dimensi motivasi terhadap pelanggan memiliki hubungan yang kuat sebesar 0,784 begitu pula dengan dimensi proses usaha hubungan nya kuat sebesar 0,709. Selanjutnya pada dimensi pengetahuan terhadap dimensi keuangan, dimensi pelanggan dan dimensi proses usaha hubungan nya juga kuat yaitu masing-masing sebesar 0,$660 ; 0,685 ; 0,628$. Kemudian pada dimensi keahlian terhadap dimensi keuangan dan proses usaha memiliki hubungan yang kuat yaitu masing-masing sebesar 0,734 dan 0,677, sedangkan dimensi keahlian terhadap dimensi pelanggan memiliki hubungan yang sangat kuat yaitu 0,827 .

\section{Kompetensi Berpengaruh Terhadap Kinerja UMKM}

Berdasarkan hasil analisa uji t, secara parsial menunjukan bahwa ada pengaruh positif dan signifikan antara variabel kompetensi terhadap variabel kinerja UMKM. Temuan ini sejalan dengan hasil penelitian sebelumnya oleh (Apriliani O. D, R. AJ. E. P., Suparwono., 2016a), (Sulistyandari et al., 2016), dan Restiani, et.al. (2018) dalam penelitiannya menemukan bahwa kompetensi berpengaruh positif terhadap kinerja UMKM. Oleh karena itu para pelaku UMKM perlu memperhatikan kompetensi yang dimiliki oleh para sumber daya manusia yang terlibat dalam menjalankan UMKM.

\section{Kesimpulan}

Kompetensi berpengaruh positif dan signifikan terhadap kinerja UMKM, hal ini menjelaskan bahwa jika adanya peningkatan kompetensi para SDM UMKM maka terjadi peningkatan pada kinerja UMKM, sehingga pengelolaan SDM UMKM di Desa Trusmi perlu mendapat perhatian dari Pemerintah setempat terkait dengan pengembangan UMKM di Desa Trusmi yang mana akan membawa pengaruh terhadap perekonomian Desa Trusmi. Dalam meningkatkan kompetensi yang dimiliki oleh para 
SDM di UMKM Desa Trusmi Pemerintah juga memiliki peran penting yaitu dalam menyediakan pelatihan dan pengembangan serta pembinaan terhadap para pelaku UMKM dalam rangka meningkatkan kompetensi mereka sehingga kinerja UMKM dapat terus meningkat. Kemudian Pemerintah harus lebih rutin dalam memberikan kegiatan yang dapat meningkatkan kompetensi para pelaku UMKM apalagi ditengah kondisi pandemi seperti sekarang ini. 
Dampak Pengelolaan Sumber Daya Manusia Usaha Mikro, Kecil dan Menengah dari Segi Kompetensi Terhadap Kinerja UMKM (Studi Kasus: UMKM Desa Trusmi-

Cirebon)

\section{BIBLIOGRAFI}

Apriliani O. D, R. AJ. E. P., Suparwono., dan M. Trihudiyatmanto. (2016a). "Pengaruh Kompetensi Dan Orientasi Kewirausahaan Terhadap Kinerja Usaha”. Journal of Economic, Management, Accounting, and Technology. Vol. 11, No. 2, pp. 1-23.

Apriliani O. D, R. AJ. E. P., Suparwono., dan M. Trihudiyatmanto. (2016b). Pengaruh Kompetensi Dan Orientasi Kewirausahaan Terhadap Kinerja Usaha. Journal of Economic, Management, Accounting, and Technology, 11(2), 1-23.

Armstrong, Michael. (2016). Armstrong's handbook of management and leadership for HR: Developing effective people skills for better leadership and management.

Asumeng, Maxwell. (2014). Managerial competency models: A critical review and proposed holistic-domain model. Journal of Management Research, 6(4), 1-21.

Bachdar, Fadjri. (2016). Pertambangan Yang Dilakukan Oleh Masyarakat Menurut Undang-Undang Nomor 4 Tahun 2009 Tentang Pertambangan Mineral Dan Batubara. Lex Privatum, 4(3).

Dharmanegara, Ida Bagus Agung, Sitiari, Ni Wayan, \& Wirayudha, IDGN. (2016). Job competency and work environment: the effect on job satisfaction and job performance among SMEs worker. IOSR Journal of Business and Management (IOSR-JBM), 18(1), 19-26.

Hadiyatno, Didik. (2012). Pengaruh Kompetensi, Kompensasi, Dan Kepuasan Kerja Terhadap Kinerja Karyawan Pada PT. Ciomas Adisatwa Balikpapan (Effect of Competence, Compensation, and Job Satisfaction Of Employee Performance At PT. Ciomas Adisatwa Balikpapan). Prosiding Seminas, 1(2).

Jeffrey, Ignatius, \& Soleman, Mahmud. (2017). The effect of work discipline, achievement motivation and career path toward employee performance of The National Resilience Institute of The Republic of Indonesia. International Journal of Application or Innovation in Engineering \& Management (IJAIEM), 6(8).

Putra, Dwi A. D., Jasmi, Kamarul Azmi, Basiron, Bushrah, Huda, Miftachul, Maseleno, Andino, Shankar, K., \& Aminudin, Nur. (2018). Tactical steps for e-government development. International Journal of Pure and Applied Mathematics, 119(15), 2251-2258.

Rivai, Veithzal dan Ella Jauvani Sagala. (2013). Manajemen Sumber daya manusia untuk Perusahaan dari Teori ke Praktek (2nd ed.). Jakarta: PT. Raja Grafindo Persada.

Sulistyandari, Sulistyandari, Widiastuti, Ekaningtyas, \& Martini, Sri. (2016). Kompetensi Sdm Dan Pengaruhnya Terhadap Kinerja Umkm Batik Di Kabupaten Banyumas. Performance: Jurnal Personalia, Financial, Operasional, Marketing 
Dan Sistem Informasi, 23(2), 89-101.

Sulistyandari, Sulistyandari, Widiastuti, Ekaningtyas, \& Martini, Sri. (2017). Kompetensi Sdm Dan Pengaruhnya Terhadap Kinerja Umkm Batik Di Kabupaten Banyumas. Performance: Jurnal Personalia, Financial, Operasional, Marketing Dan Sistem Informasi, 23(2), 89-101.

Syafarudin, Afriapollo, \& Sudiarditha, I. Ketut R. (2018). Analisis Kompetensi Strategi Sumber Daya Manusia Pada Pelaku Usaha Industri Kreatif. Jurnal Ecodemica: Jurnal Ekonomi, Manajemen, Dan Bisnis, 2(2).

Widaningrum, Dyah Lestari dan Ivanaldy Kabul. (2014). Implementasi Balanced Scorecard Pada Unit Usaha Kecil Menengah: Studi Kasus Sebuah Restoran Di Jakarta. ComTech, 5(2), 1031-1040.

Widjadja, Yani Restiani, Alamsyah, Doni Purnama, Rohaeni, Heni, \& Sukanjie, Bambang. (2018). Peranan Kompetensi SDM UMKM Dalam Meningkatkan Kinerja UMKM Desa Cilayung Kecamatan Jatinangor, Sumedang. Jurnal Abdimas BSI: Jurnal Pengabdian Kepada Masyarakat, 1(3). 